\title{
KARAKTERISTIK PENINGKATAN KEMAMPUAN LELAH AISI 1045 TERHADAP PROSES HARDENING
}

\section{Rizky Sulistyawan Sofian Junaida}

Universitas Tarumanagara Jakarta, Indonesia

Email: rizky.515160045@stu.untar.ac.id

\begin{tabular}{l}
\hline INFO ARTIKEL \\
\hline Diterima \\
12 Februari 2021 \\
Direvisi \\
20 Februari 2021 \\
Disetujui \\
15 Maret 2021 \\
\hline
\end{tabular}

\section{Keywords:}

Fatigue test; rotary bending; medium carbon steel AISI 1045.

\section{ABSTRACT}

Steel has an important role in an industry where many engine component designs use this material. The mechanical properties of the material are sufficiently capable of various field applications in various applications. The efficiency and effectiveness of the steel itself is always a consideration in selecting the material according to its considerations. This is to determine the hardening process that occurs in AISI 1045 steel materials. Comparing the properties of AISI 1045 steel material with before and after the heat treatment process. Methodology The research was conducted using comparison of literature data in international journal media regarding the comparison of AISI 1045 Steel heat treatment process and obtaining data from the test results contained in the journal, namely, Hardening, Holding Time, Quenching comparing the results of data obtained from secondary data. From the results of the research that has been done it can be seen that the long holding time in the hardening process does not always affect the hardness of AISI 1045 steel. The kitchen radiates heat, the temperature in the heating chamber is not always stable during long holding times, the carbon is uneven as it diffuses into the specimen during the hardening process. The results of the AISI 1045 steel research were seen from the hardness test before and after.

\footnotetext{
ABSTRAK

Baja memiliki peran penting dalam industri di mana banyak desain komponen mesin menggunakan bahan ini. Sifat mekanis bahan cukup mampu melakukan berbagai aplikasi lapangan dalam berbagai aplikasi. Efisiensi dan efektivitas baja itu sendiri selalu menjadi pertimbangan dalam memilih bahan sesuai dengan pertimbangannya. Hal ini untuk menentukan proses pengerasan yang terjadi pada bahan baja AISI 1045. Membandingkan
} 


\begin{tabular}{ll}
\hline & sifat bahan baja AISI 1045 dengan sebelum dan sesudah \\
& proses perlakuan panas. Metodologi penelitian \\
& dilakukan dengan menggunakan perbandingan data \\
& literatur di media jurnal internasional mengenai \\
& perbandingan proses perlakuan panas AISI 1045 Steel \\
& dan mendapatkan data dari hasil tes yang terkandung \\
& dalam jurnal, yaitu Hardening, Holding Time, \\
& Quenching membandingkan hasil data yang diperoleh \\
& dari data sekunder. Dari hasil penelitian yang telah \\
& dilakukan dapat dilihat bahwa waktu penahanan yang \\
& lama dalam proses pengerasan tidak selalu memengaruhi \\
& kekerasan baja AISI 1045. Dapur memancarkan panas, \\
& suhu di ruang pemanas tidak selalu stabil selama waktu \\
& penahanan yang lama, karbon tidak rata karena \\
Kata Kunci: & kenyebar ke dalam spesimen selama proses pengerasan. \\
Tes & Hasil penelitian baja AISI 1045 terlihat dari tes \\
pembengkokan putar; baja & karbon sedang AISI 1045. \\
karberasan sebelum dan sesudahnya.
\end{tabular}

Coresponden Author

Email: rizky.515160045@ stu.untar.ac.id Artikel dengan akses terbuka dibawah lisensi

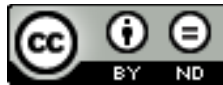

\section{Pendahuluan}

Baja sangat memiliki peranan yang penting dalam dunia industri di mana banyak rancangan komponen mesin pabrik menggunakan material tersebut (WIJAYA, 2018) . Sifat mekanik yang dimiliki material ini cukup mampu untuk berbagai penggunaan lapangan dalam berbagai aplikasi. Efisiensi dan efektifitas dari baja itu sendiri selalu menjadi pertimbangan dalam pemilihan material sesuai dengan pemakaiannya (Sugiarto, 2013). Pada kasus rancang bangun suatu konstruksi mesin, selalu diperlukan sifat bahan dengan tujuan agar komponen yang dirancang dapat bekerja secara optimal, dan dapat memenuhi persyaratan fungsi dari konstruksi maupun kekuatannya dalam menerima beban. Sifat yang dikenal dengan kelelahan bahan, perlu diteliti karena sangat penting untuk menentukan umur konstruksi berdasarkan kelelahan (Mandiangan, 2019). Poros berfungsi untuk meneruskan tenaga baik berupa puntiran, torsi maupun bending dari suatu bagian ke bagian yang lain (Wibowo et al., 2020). Akibat beban tersebut poros mengalami pembebanan yang terus berulang suatu poros sering mengalami kegagalan dalam operasinya. Kegagalan akibat beban berulang sangat tidak diinginkan karena tanda-tanda akan terjadinya kegagalan tidak dapat diketahui secara langsung (Pujono \& Fauzi, 2020).

Kegagalan ini dapat berupa crack yang terus berkembang hingga terjadi perambatan crack yang kemudian menjadi patah (Ramadhan, 2017). Logam yang mengalami pembebanan dengan tegangan dinamis dan berulang dalam jangka waktu yang lama, perlu dilakukan pengujian untuk memprediksi kegagalan material(Pratowo \& 
Surya, 2019). Salah satu tipe pengujian untuk memprediksi kegagalan material akibat beban berulang (fatik) adalah pengujian dengan menggunakan mesin uji fatik rotary bending (Rusdi \& Baso, 2017). Identifikasi masalah dalam penelitian "Karakteristik peningkatan kemampuan lelah AISI 1045 terhadap proses perlakuan panas" yaitu sebagai berikut: Bagaimana pengaruh perlakuan panas terhadap sifat mekanik baja karbon sedang? dan Bagaimana pengaruh variasi suhu dan variasi penahanan waktu (holding time) pada saat pemanasan?

Tujuan yang ingin dicapai dalam penelitian ini adalah untuk mengetahui proses Hardening yang terjadi pada bahan material baja AISI 1045. Membandingkan sifat-sifat material baja AISI 1045 dengan sebelum dan sesudah dilakukan proses perlakuan panas. Paduan antara besi (Fe) dan karbon (C) dapat disebut dengan baja penambahan paduan lainnya. Baja paling banyak digunakan di dunia industri seperti komponen otomotif, tranformer listrik dan untuk proses manufaktur lainnya seperti proses pembuatan lembaran besi, proses ekstrusi dan lain-lain. Dasar pemilihan baja tergantung pemakaian seiring dengan terus berkembangnya industri otomotif dan kebutuhan masyarakat akan kendaraan bermotor, komponen permesinan, ban konstruksi dan bidang lainnya terutama didasarkan pada sifat mekaniknya jika sifat logam sangat keras sangat sulit dalam pembentukannya. baja memiliki kemampuan pengerasan (hardenability) rentangan yang besar sehingga dapat sesuai dengan yang diinginkan disesuaikan dengan sifat mekanik yang dari baja itu. Paduan logam baja karbon rendah yang terdiri besi (Fe) dan unsurunsur karbon (C), Silikon (Si), Mangan (Mn), Phosfor (P) dan unsur lainnya. Di dalam pengembangan material salah satu tujuan terpenting adalah untuk kita menentukan apakah struktur dan sifat-sifat material itu optimum, agar daya tahan yang dicapai maksimum sifat utama baja. Hipotesis ketahanan lelah baja AISI 1045 akan meningkat melalui proses hardening dengan memperoleh kehalusan permukaan pada variasi temperatur hardening.

\section{Metode Penelitian}

Metodologi penelitian yang dilakukan dengan menggunakan komparasi data literatur dalam media jurnal internasional mengenai perbandingan proses perlakuan panas baja AISI 1045 dan mendapatkan data dari hasil pengujian yang terdapat dalam jurnal yaitu, Hardening, Holding Time, dan Quenching membandingkan hasil data yang didapat dari data sekunder. Setelah itu data tersebut diubah menjadi grafik yang berguna untuk melihat perubahan pemanasan material. Membuat analisa berdasarkan data dan grafik yang telah diperoleh untuk dijadikan sebagai kesimpulan data. 


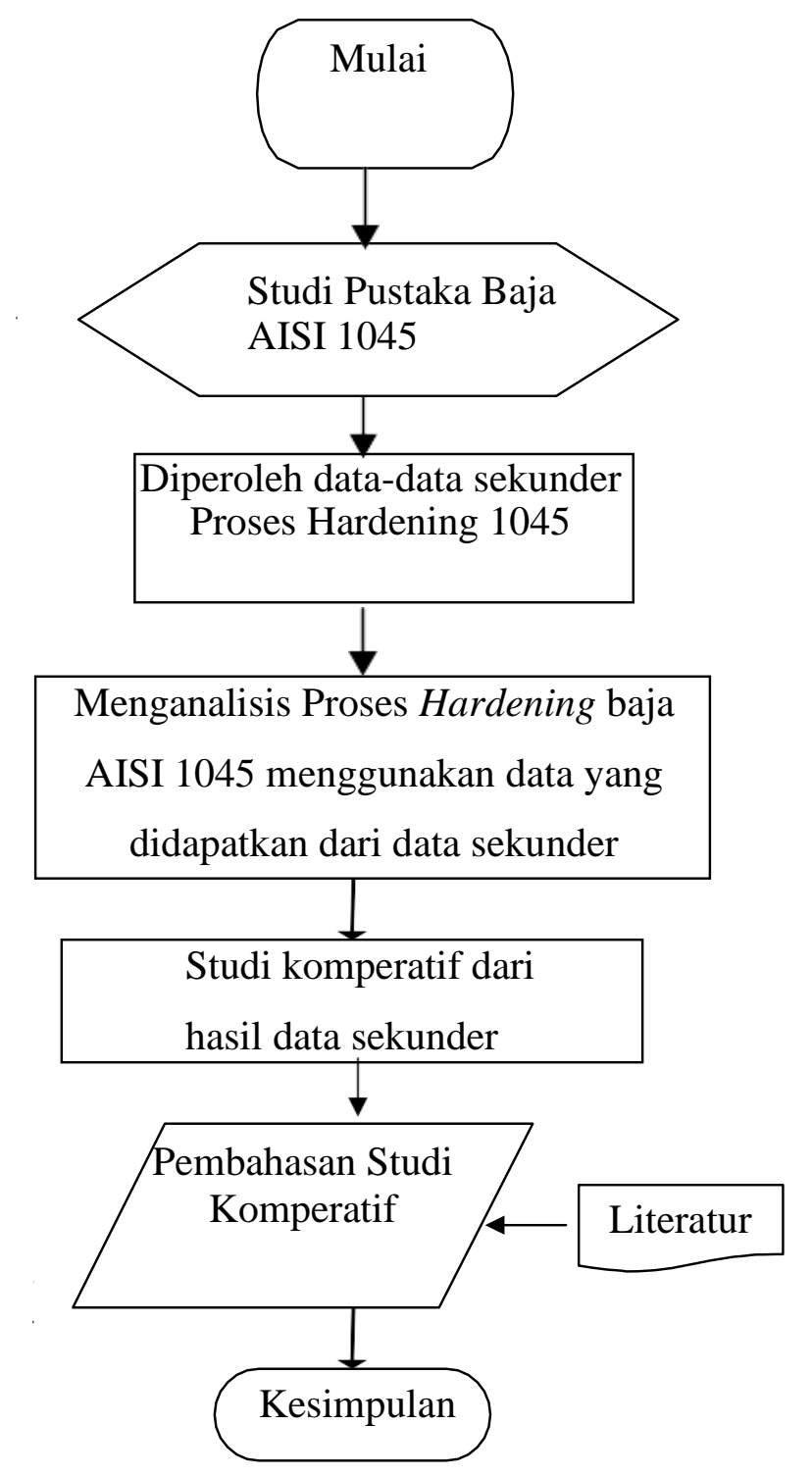

\section{Gambar 1}

\section{Flowchart diagram alir penelitian pengolahan data}

\section{Hasil dan Pembahasan}

\section{A. Perbandingan 1}

Dari pengujian fatik pada Baja AISI 1045 yang telah dilakukan diperoleh hasil pengujian sebagai berikut:

Baja karbon sedang AISI 1045 (raw material) 


\section{Tabel 1}

Hasil Pengujian Baja Karbon Sedang AISI 1045

\begin{tabular}{ccccc}
\hline No & $\boldsymbol{\sigma}(\mathbf{M p a})$ & Siklus & Rpm & t (menit) \\
\hline $\mathbf{1}$ & 125 & 519120 & 2882 & 180 \\
\hline $\mathbf{2}$ & 187,5 & 518940 & 2881 & 180 \\
\hline $\mathbf{3}$ & 250 & 205703,4 & 2882 & 71,4 \\
\hline $\mathbf{4}$ & 312,5 & 127184,4 & 2883 & 44,1 \\
\hline $\mathbf{5}$ & 375 & 89342 & 2881 & 31 \\
\hline
\end{tabular}

Dari hasil pengujian kelelahan (fatik) yang dilakukan terhadap benda uji dibentuk dalam kurva S-N yang terlihat pada gambar 2 berikut ini:

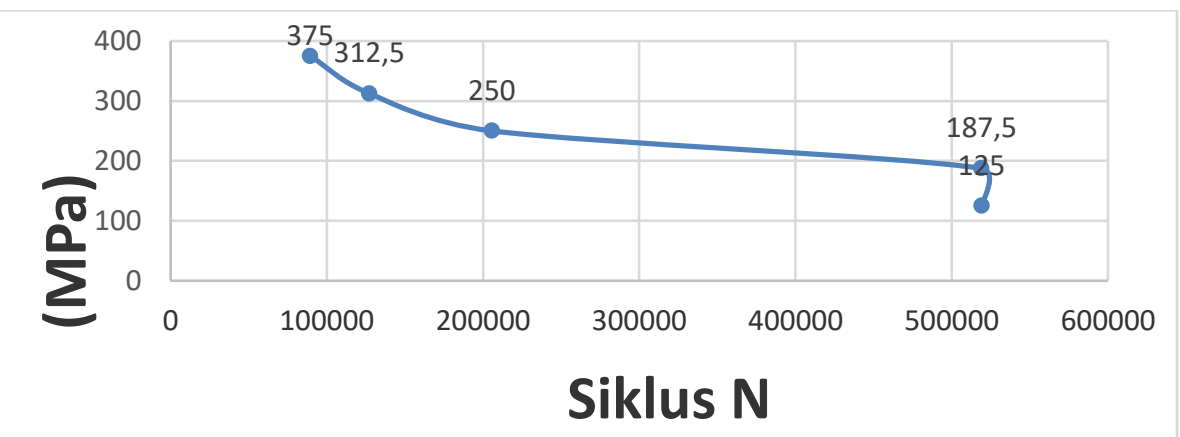

Grafik 1

Kurva S-N Pengujian Kelelahan (Fatik) Baja Karbon Sedang AISI 1045

Dari diagram S-N yang terlihat pada grafik 2 dapat ditentukan persamaan garisnya dengan menggunakan semi log. Persamaaan garis tersebut secara umum dinyatakan oleh Dowling adalah sebagai berikut:

$$
\mathrm{S}=\mathrm{B}+\mathrm{C} \text { In }(\mathrm{Nf})
$$

Garis log yang terbentuk merupakan pendekatan tiga titik hubungan tegangan dan siklus patah yang diperoleh dari pengujian (Rusdi \& Baso, 2017). Garis log yang terbentuk terdapat penyimpangan pada pengujian dengan tegangan $312,5 \mathrm{MPa}$ di mana garis log berada diatas (Tan, 2016). Garis log diatas menunjukkan siklus patah yang terjadi pada waktu pengujian lebih cepat. Hal ini karena terjadi crack.

Dari grafik diatas diperoleh persamaan untuk baja karbon sedang AISI 1045 (raw material) adalah:

$$
\sigma=-148 \ln (\mathrm{Nf})+2066
$$

Persamaan 3 dapat digunakan untuk menentukan batas ketahanan fatik (endurance limit) dimana batas ketahanan fatik (endurance limit) dari baja karbon sedang AISI 1045 ditentukan oleh banyaknya siklus (Nf). Cara mencari banyaknya siklus dari persamaan 3 adalah sebagai berikut :

$$
\begin{gathered}
\sigma=-148 \ln (\mathrm{Nf})+2066 \\
148 \ln (\mathrm{Nf})=2066-\sigma \\
\ln (\mathrm{Nf})=2066-\sigma / 148
\end{gathered}
$$


Tegangan yang besar akan menghasilkan siklus patah yang rendah, sesuai dengan persamaan 3 menunjukan tegangan berbanding terbalik dengan siklus patah (Tawaf et al., 2015). Dengan menggunakan persamaan 3 (tiga) maka dapat ditentukan siklus patah pada pengujian dengan tegangan yang diberikan 312,5 MPa sebagai berikut:

$$
\begin{gathered}
\sigma=-148 \ln (\mathrm{Nf})+2066 \\
-148 \ln (\mathrm{Nf})=\sigma-2066 \\
\ln (\mathrm{Nf})=(\sigma-2066) /-148 \\
\ln (\mathrm{Nf})=(312,5 \mathrm{MPa}-2066) /-148 \\
\mathrm{Nf}=139800,68 \text { siklus }
\end{gathered}
$$

Siklus yang diperoleh adalah 139800,68 siklus, sedangkan pada pengujian diperoleh siklus 127184,4 siklus, ini berarti siklus pada pengujian lebih rendah(Suhartono, 2018). Jika dilihat pada tabel 1 menunjukan pada pengujian dengan tegangan 312,5 MPa memiliki kekasaran permukaan yang lebih tinggi dari 5 pengujian yang lain.

\section{Tabel 2}

Hasil Pengujian Baja Karbon Sedang AISI 1045 Heat Treatment

\begin{tabular}{ccccc}
\hline No & $\boldsymbol{\sigma ( M P a )}$ & Siklus & Rpm & t(menit) \\
\hline $\mathbf{1}$ & 271,53 & 518760 & 2882 & 180 \\
\hline $\mathbf{2}$ & 407,295 & 15182,87 & 2881 & 5,27 \\
\hline $\mathbf{3}$ & 543,06 & 10836,32 & 2882 & 3,76 \\
\hline $\mathbf{4}$ & 678,825 & 6515,58 & 2883 & 2,26 \\
\hline $\mathbf{5}$ & 814,59 & 4321,5 & 2881 & 1,5 \\
\hline
\end{tabular}

Dari hasil pengujian kelelahan (fatigue) yang dilakukan terhadap benda uji disajikan dalam bentuk kurva S-N yang terlihat pada gambar 4.2 berikut ini:

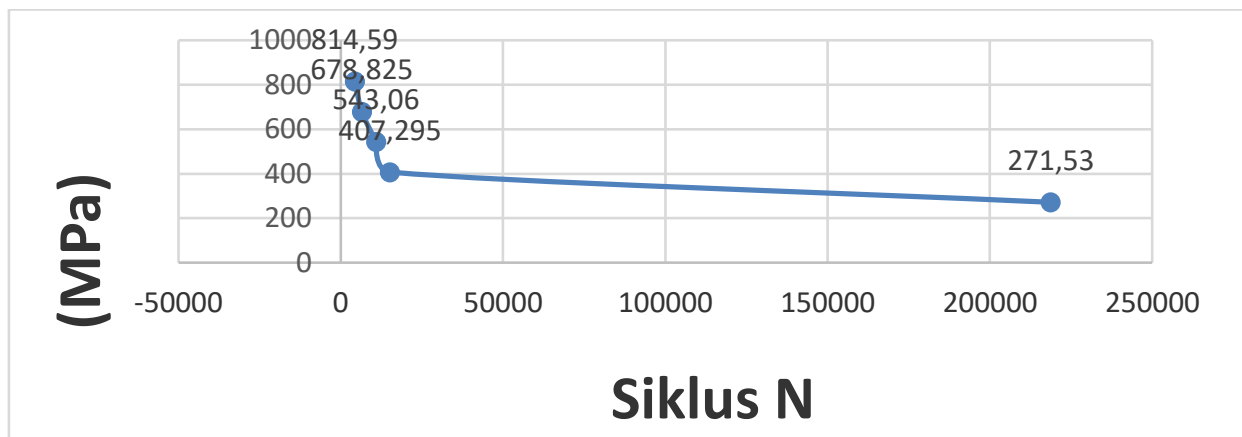

Grafik 2

Kurva S-N Pengujian Kelelahan (Fatik) Baja Karbon Sedang AISI 1045, Heat Treatment

\section{B. Perbandingan 2}


Pada sampel 1 ini pada suhu $30^{\circ} \mathrm{C}$ dan tidak dilakukan tempering pada sampel 1 dan tidak perlu dilakukan quenching oli pada sampel 1. Pada sampel 2 terlebih dahulu pada suhu maksimum $925^{\circ} \mathrm{C}$ dan telah di quench dengan oli untuk pendinginan. Untuk waktu 15 menit dan setelah didinginkan dilakukan tempering pada sampel 2 suhu $500^{\circ} \mathrm{C}$ selama 90 menit. Setelah dilakukan temper pada sampel 2, sampel ketiga yaitu sampel 3 juga pada suhu maksimum $925^{\circ} \mathrm{C}$ serta dilakukan quenching oli pada sampel 3 untuk pendinginan selama 15 menit dan dilakukan temper pada sampel tersebut pada suhu $250{ }^{\circ} \mathrm{C}$ selama 105 menit.

Tabel 3

Proses Perlakuan Panas

\begin{tabular}{cccccc}
\hline S.No & $\begin{array}{c}\text { Sample } \\
(\mathbf{S})\end{array}$ & $\begin{array}{c}\text { Max } \\
\text { Temperature }(\mathbf{C})\end{array}$ & $\begin{array}{c}\text { Oil } \\
\text { Quenching } \\
\text { time (min) }\end{array}$ & $\begin{array}{c}\text { Tempering } \\
\text { Temperature } \\
(\mathbf{C})\end{array}$ & $\begin{array}{c}\text { Temperating } \\
\text { time (min) }\end{array}$ \\
\hline $\mathbf{1}$ & $\mathrm{S}_{1}$ & 30 & - & - & - \\
\hline $\mathbf{2}$ & $\mathrm{S}_{2}$ & 952 & 15 & 500 & 90 \\
\hline $\mathbf{3}$ & $\mathrm{S}_{3}$ & 925 & 15 & 250 & 105 \\
\hline
\end{tabular}

Pada hasil properti, properti pertama adalah kekuatan tarik ultimat yang memiliki tiga hasil yaitu sampel $S_{1}, S_{2}$ dan $S_{3}$, dimana sampel 1 memiliki kuat tarik ultimit $851,80 \mathrm{~N} / \mathrm{mm}^{2}$ dan sampel 2 meningkatkan kekuatannya dari sampel 1 , kekuatan tarik ultimit sampel $2892,00 \mathrm{~N} / \mathrm{mm}^{2}$ dan dalam kasus sampel 3, kekuatan tarik ultimat sampel 3 memiliki lebih dari sampel 1 dan sampel 2, yaitu sampel 3 memiliki kekuatan tarik ultimat adalah 913,20 N/mm². Dalam kekuatan luluh, kekuatan luluh sampel 1 adalah 843,70 N/mm² dan kekuatan luluh sampel 2 adalah $689,10 \mathrm{~N} / \mathrm{mm}^{2}$ dan kekuatan luluh sampel 3 adalah 643,60 N/mm ${ }^{2}$. Di properti ketiga, nilai HRC dari sampel 2 adalah 29 HRC dan nilai HRC sampel 3 adalah 41 HRC yang juga mengalami peningkatan, tetapi untuk sampel 1, HRC tidak dapat dihitung, karena bahan ini tidak mengeras atau mengalami tempering. HRC tidak dapat menghitung karena jika kurang dari 25 HRC maka hasilnya tidak benar dan pada properti keempat kekerasan brinell, kekerasan brinell dari sampel 1 adalah 239 hingga 241 BHN, tetapi dalam kasus sampel 1 dan sampel 2, nilai HRC diperoleh, tetapi BHN tidak membawa nilai yang sama, karena ketika beban HRC adalah pakai bola BHN kemudian putus karena tidak mengontrol beban HRC. Oleh karena itu, nilai BHN tidak dapat dihitung. Bola BHN dapat mentolerir beban maksimal 50-70 $\mathrm{kg}$. 
Tabel 4

Hasil Property

\begin{tabular}{|c|c|c|c|c|}
\hline S.No & Properties & Sample1(S1) & Sample $\left(\mathbf{S}_{2}\right)$ & Sample( $\left(\mathbf{S}_{3}\right)$ \\
\hline \multirow[t]{2}{*}{1} & UTS & 851.80 & $892.00 \mathrm{~N} / \mathrm{mm}^{2}$ & 913.20 \\
\hline & & $\mathrm{N} / \mathrm{mm}^{2}$ & & $\mathrm{~N} / \mathrm{mm}^{2}$ \\
\hline \multirow[t]{2}{*}{2} & YS & 843.70 & $689.10 \mathrm{~N} / \mathrm{mm}^{2}$ & 643.60 \\
\hline & & $\mathrm{N} / \mathrm{mm}^{2}$ & & $\mathrm{~N} / \mathrm{mm}^{2}$ \\
\hline 3 & HRC & - & 29 HRC & $41 \mathrm{HRC}$ \\
\hline 4 & $\mathrm{BHN}$ & $\begin{array}{c}239-241 \\
\text { BHN }\end{array}$ & - & - \\
\hline
\end{tabular}

Dalam grafik temperatur, berikut adalah batang biru dan merah pada grafik. Warna biru menunjukkan suhu maksimum dan warna merah menunjukkan suhu temperatur sampel. Sampel 1 yang berada pada suhu ruang $30^{\circ} \mathrm{C}$ dan sampel 2 dan sampel 3 yang memiliki suhu maksimum $925^{\circ} \mathrm{C}$ ditunjukkan dengan batang biru dan suhu tempering sampel 2 adalah $500^{\circ} \mathrm{C}$ yang ditunjukkan dengan batang merah dan suhu tempering sampel 3 bersuhu $250^{\circ} \mathrm{C}$ (Jerold \& Kumar, 2012).

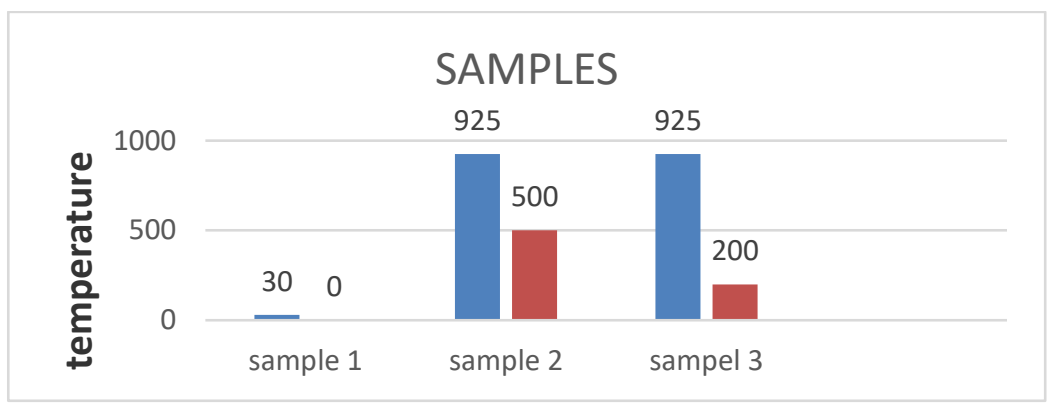

Grafik 3

Temperatur Tempering

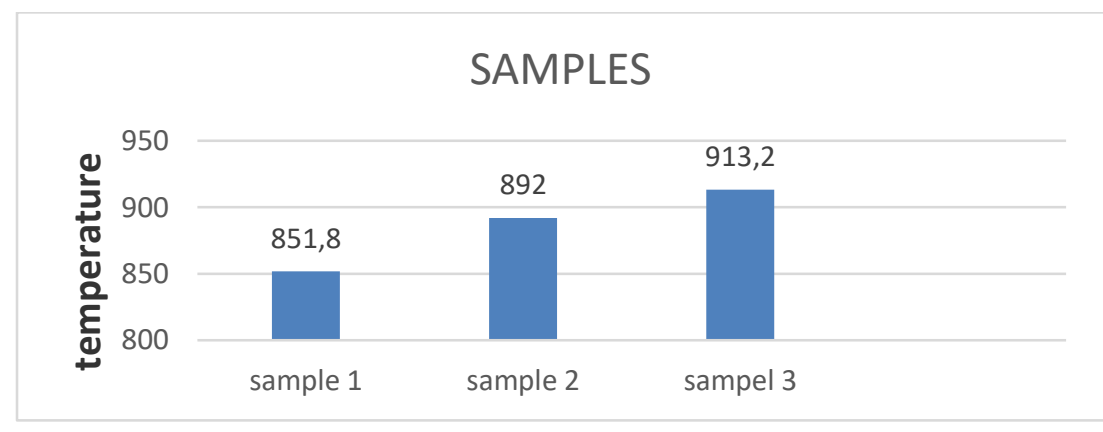

Grafik 4

Kekuatan Tarik Ultimat 


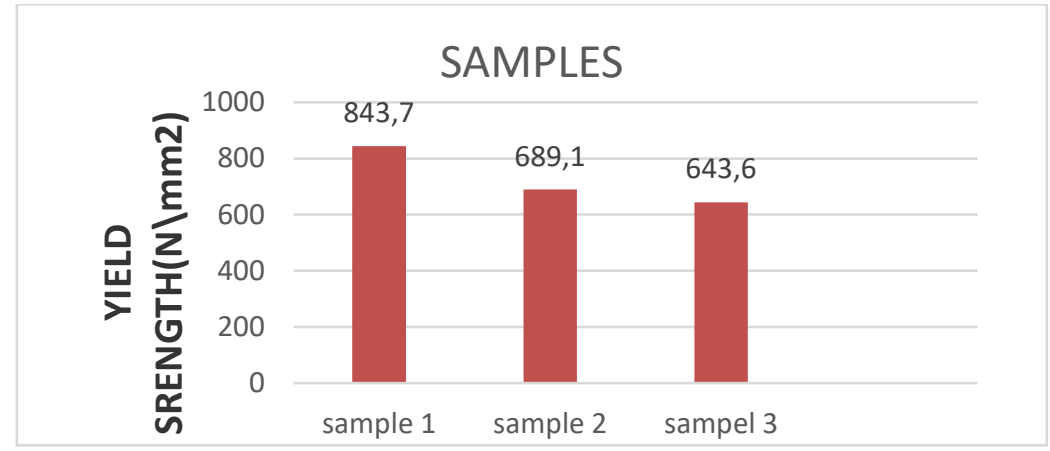

Grafik 5

Kekuatan Luluh

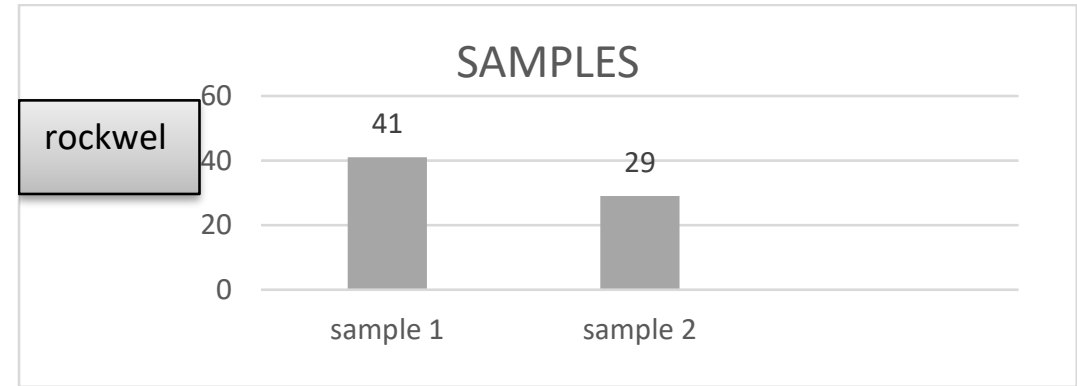

\section{Grafik 6}

\section{Perbandingan 3}

\section{Kekerasan Rockwell}

Grafik nilai rata-rata kekerasan baja AISI 1045 sebelum dan sesudah perlakuan hardening dengan variasi waktu tahan.

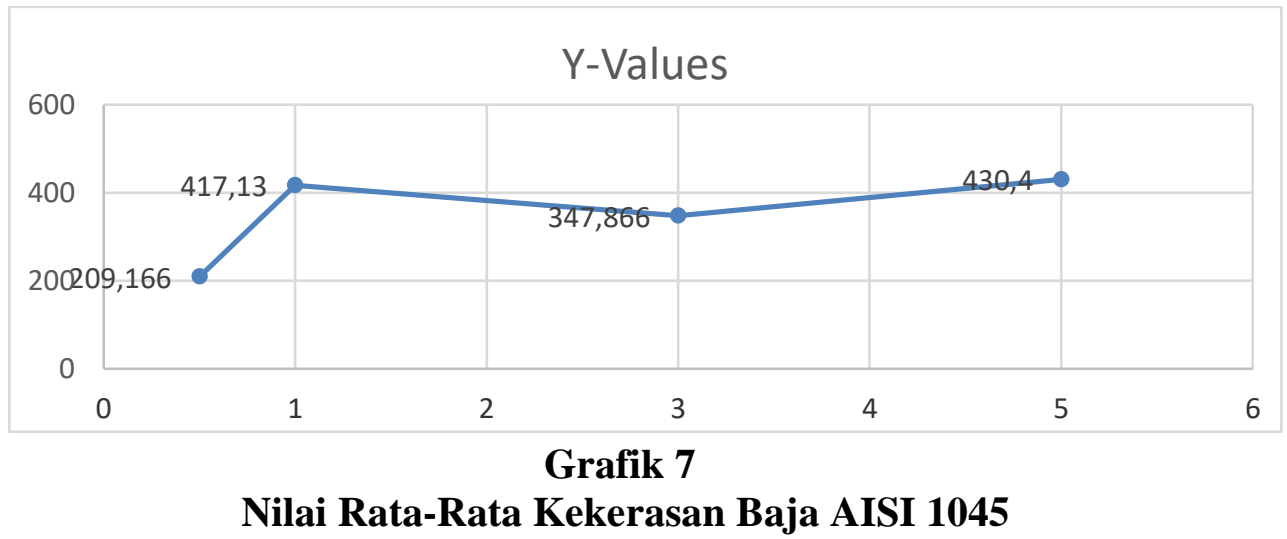

Semakin lama waktu tahan hardening maka akan didapat kekerasan yang semakin keras (Siregar \& Nasution, 2012). Tetapi dari hasil penelitian yang telah dilakukan dapat dilihat bahwa waktu tahan yang lama pada proses hardening tidak selalu berpengaruh terhadap semakin kerasnya baja AISI 1045 (Ye et al., 2012). Dari penelitian ini dapat diketahui banyak sekali faktor-faktor yang memengaruhi kekerasan baja AISI 1045 saat penahanan waktu pada proses hardening yaitu kemampuan memancarkan panas, suhu pada pemanas yang tidak selalu stabil saat 
penahanan waktu hardening yang lama, karbon yang tidak merata saat berdifusi ke dalam spesimen pada proses hardening (Avilés et al., 2013). Hasil penelitian baja AISI 1045 dilihat dari uji kekerasan sebelum dan sesudah.

\section{Kesimpulan}

Berdasarkan analisis data sekunder yang didapat dari pembahasan hasil dari penelitian dapat disimpulkan bahwa siklus yang didapat adalah 139800,68 siklus dan pengujian yang didapat dari siklus yaitu 127184,4 siklus yaitu siklus saat pengujian lebih rendah. Jika dilihat pada tabel 4 terlihat bahwa pada pengujian dengan tegangan 312,5 MPa memiliki kekasaran permukaan yang lebih tinggi dari 5 pengujian lain dan semakin lama waktu tahan proses hardening didapat kekerasan yang semakin keras. Tetapi dari hasil penelitian yang telah dilakukan dapat dilihat bahwa waktu tahan yang lama pada proses hardening tidak selalu berpengaruh terhadap semakin kerasnya baja AISI 1045, mampu melakukan pengujian fatik selama 3 jam pada tegangan $20 \%$ dan $30 \%$ dan dilakukan pengujian fatik dengan suhu proses harderning berada disekitar suhu $\left(820^{\circ} \mathrm{C}-\right.$ $\left.860^{\circ} \mathrm{C}\right)$. 


\section{BIBLIOGRAFI}

Avilés, R., Albizuri, J., Rodríguez, A., \& De Lacalle, L. N. L. (2013). Influence Of LowPlasticity Ball Burnishing On The High-Cycle Fatigue Strength Of Medium Carbon Aisi 1045 Steel. International Journal Of Fatigue, 55, 230-244.

Jerold, B. D., \& Kumar, M. P. (2012). Experimental Comparison Of Carbon-Dioxide And Liquid Nitrogen Cryogenic Coolants In Turning Of Aisi 1045 Steel. Cryogenics, 52(10), 569-574.

Mandiangan, F. Y. (2019). Rancang Bangun Simulator Penyaringan Bahan Bakar Dengan Menggunakan Katup Bypass Pada Sistem Distribusi Bahan Bakar Pesawat Terbang (Perawatan Dan Perbaikan)(Perawatan Dan Perbaikan). Politeknik Negeri Sriwijaya.

Pratowo, B., \& Surya, I. (2019). Analisis Kekuatan Fatik Baja Karbon Rendah Sc10 Dengan Tipe Rotary Bending. Jurnal Teknik Mesin, 7(1).

Pujono, P., \& Fauzi, R. W. N. (2020). Rancang Bangun Mesin Flushing Oil. Bangun Rekaprima: Majalah Ilmiah Pengembangan Rekayasa, Sosial Dan Humaniora, 6(1, April), 15-26.

Ramadhan, Y. P. P. (2017). Analisis Pengaruh Variasi Waktu Tahan Dan Media Pendingin Proses Hardening Pada Sifat Kekerasan Baja Aisi 8655 Sebagai Solusi Kegagalan Pada Hammer Crusher. Institut Teknologi Sepuluh Nopember.

Rusdi, N., \& Baso, N. (2017). Kaji Eksperimental Sustainable Machining Pada Proses Pembubutan Baja Aisi 1045.

Siregar, A., \& Nasution, M. (2012). Peningkatan Sifat Sifat Fatik Dan Mekanis Baja Chromized Dengan Proses Perlakuan Panas.

Sugiarto, T. (2013). Analisis Uji Ketahanan Lelah Baja Karbon Sedang Aisi 1045 Dengan Heat Treatment (Quenching) Dengan Menggunakan Alat Rotary Bending. Jurnal Ilmiah Teknik Mesin, 1(3).

Suhartono, H. A. (2018). Karakterisasi Sifatlelah Siklus Rendah Uniaksial Pada Paduan Aluminium Ekstrusi. Jurnal Sains Materi Indonesia, 12(3), 229-233.

Tan, H. (2016). Pengaruh Heat Treatment Dengan Variasi Media Quenching Air Dan Oli Terhadap Struktur Mikro Dan Nilai Kekerasan Baja Pegas Daun Aisi 6135.

Tawaf, N., Suprapto, W., \& Purnowidodo, A. (2015). Analisis Fatigue Failure Suhu Rendah Struktur Batang Duralumin Dengan Mesin Siklus Bending. Rekayasa Mesin, 5(3), 239-245.

Wibowo, A. F., Hidayat, M. I. P., \& Rochiem, R. (2020). Analisa Faktor Intensitas 
Karakteristik Peningkatan Kemampuan Lelah Aisi 1045 terhadap Proses Hardening

Tegangan Dan Usia Siklus Pada Simulasi Perambatan Retak Komponen Poros Menggunakan Metode Smart Crack Growth. Jurnal Teknik Its, 8(2), F121-F126.

Wijaya, S. (2018). Perencanaan Mesin Uji Lelah Rotating Bending Untuk Baja Aisi 1045. Unimed.

Ye, G. G., Xue, S. F., Ma, W., Jiang, M. Q., Ling, Z., Tong, X. H., \& Dai, L. H. (2012). Cutting Aisi 1045 Steel At Very High Speeds. International Journal Of Machine Tools And Manufacture, 56, 1-9. 